\title{
NONLINEAR STRUCTURAL ANALYSIS OF A 2D CUT-AND-COVER TUNNEL EXPOSED TO FIRE
}

\author{
Omid Pouran ${ }^{\mathrm{a}, \mathrm{b}}$, Reinhard Harte ${ }^{\mathrm{a}, \mathrm{b}}$, Carsten Peter ${ }^{\mathrm{c}}$ \\ ${ }^{\mathrm{a} B e r g i s c h e ~ U n i v e r s i t a ̈ t ~ W u p p e r t a l, ~ I n s t i t u t e ~ f o r ~ S t a t i c s ~ a n d ~ D y n a m i c s ~ o f ~ S t r u c t u r e s, ~ W u p p e r t a l, ~ G e r m a n y ~}$ \\ ${ }^{\mathrm{b}}$ Kraetzig \& Partner Engineering Consultants, Bochum, Germany \\ ${ }^{\mathrm{c}}$ IMM Maidl \& Maidl Engineering Consultants, Bochum, Germany
}

\begin{abstract}
Behaviour of cut-and-cover tunnels exposed to fire should be analysed by using a realistic model which takes account ofsimultaneous mechanical and thermal effects acting on the structure. This has been performed by 2D structural modelsfor a 2-cell tunnel with the aid of FE software package called SOFiSTiK (SOFiSTiK, 2014), in parallel, for two types of elements, beam and plate elements, as a scope of research project financed by BAST. The two considered models were levelled in terms of boundary conditions and the possible mechanical behaviour as well as mesh generation aspects.A nonlinearthermo-mechanical analysis has been performed considering predamaged effects on the cross sectionsby taking into account 10 and 15-minute time intervals for a whole duration of 90 minutes. The results of both models are in an acceptable agreement with each other,but they deviate from the simplified, linear-elastic calculation method considering a constant temperature gradient, $\Delta \mathrm{T}_{\mathrm{M}}=50 \mathrm{~K}$,proposed by ZTV-ING Part 5 (BASt, 2013). To improve this method, a linear interpolation of different $\Delta \mathrm{T}_{\mathrm{M}}$-values with respect to the thickness of theconcrete member has been introduced.
\end{abstract}

Keywords:Tunnel, cut-and-cover, fire, nonlinear, high temperatures,

\section{INTRODUCTION}

In the event offire, structural behaviour of road tunnelsmay be affecteddue to imposed thermal effectsto high extent and might, consequently, result in failure of the structure. This riskcan be minimized by means of appropriate fire design which provides sufficient passive fire protection for the structure. Further, in reinforced concrete structures, fire mainly results in spalling of concrete. This implies reduction of cross section thickness and, as a consequence, decreaseof the concrete cover, which may expose the reinforcementdirectly to the fire.To avoid spalling, in Germany, polypropylene-fibres (PP-fibres) are usually used to improve the concrete for both new road and railway tunnels. The addition ofPP-fibres, verifiably,reduces the inner pore pressure in the concrete and by this decreases the risk and impact of concrete spalling, as various small and large scale fire tests have shown.Therefore, in the project'scalculation, it is assumed that a sufficient amount of PP fibres had been added in the concrete mixture and effects due to spallingare negligible.

A simplified calculation method for structural fire proof is givenin ZTV-ING(BASt, 2013), the applicable code for road tunnels in Germany, where the structural fire resistance can be verified by using atemperature-gradient, $\Delta \mathrm{T}_{\mathrm{M}}=50 \mathrm{~K}$, approach in walls and ceilings.

The structure investigated in the research project is a 2-cell reinforced concrete tunnel as illustrated in figure 1, including the standard loadings like dead and traffic loads and soil pressure.To design the tunnel structure for serviceability and ultimate limit states, linear analysis is performed by taking into account the worst case of combination of actions according to EN 1992-1-1. The calculations are usually performed by 2D structural models, either beam or plate models, as the tunnel sections are constructed in blocks, resulting, therefore, in load-bearing in transverse direction. Although, if there exist differences in loads, sub soil and geometry in longitudinal (along the road) direction of the tunnel, calculations with 3D structural models will be necessary. 


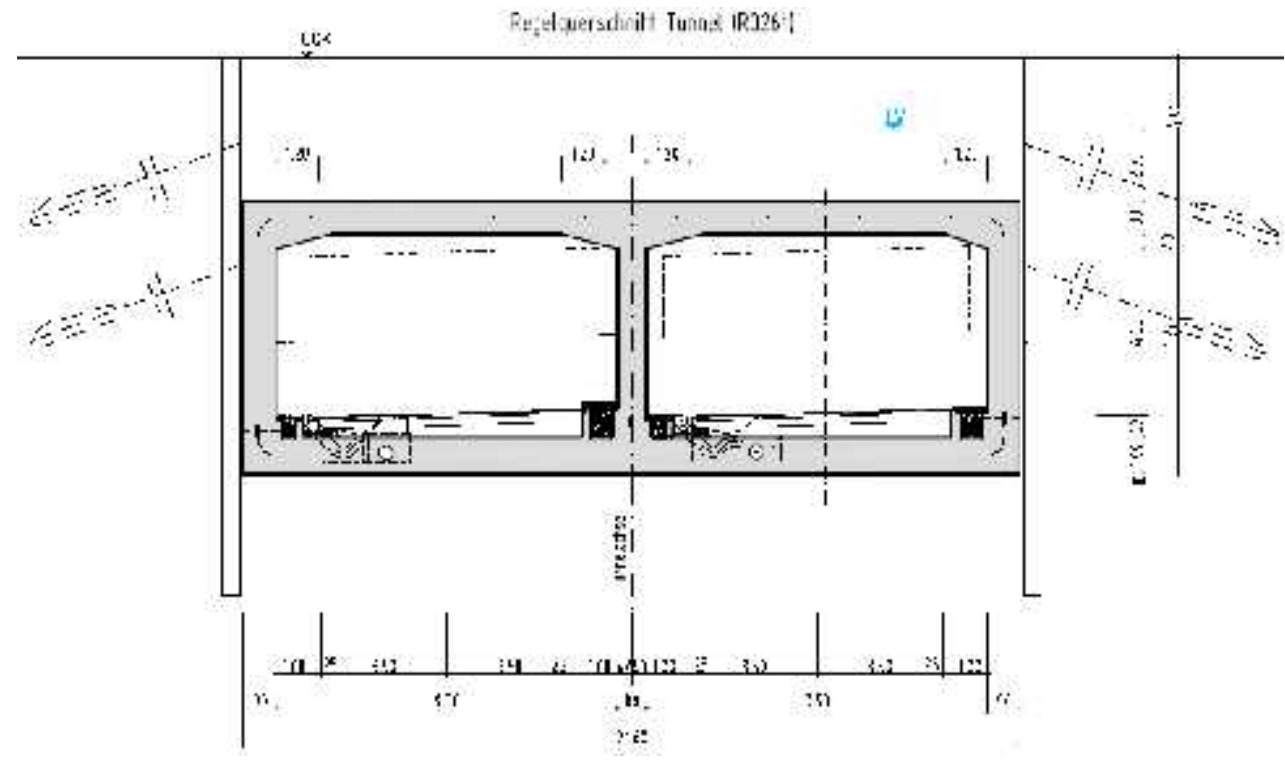

Fig.1 2-cell tunnel cross section

To simulate the fire action, a fire exposure curve is to be applied on walls and ceilings, whereas the bottom floor is protected by the floor cover. For verification of ULS criteria during fire, structural calculations are performed for the accidental design situation. In this case, the indirect thermal effectsresult from the forcesdue to restrained thermal elongation or rotation dependent on the temperature distribution in the concretecross section. The superposition of thermal effects in different time steps with the most unfavorable effects from standard load combinations is performed as so calledthermo-mechanical analysis. This analysis is based on an iterative nonlinear calculation to determine the internal forces by considering the simultaneous decrease of stiffness of each cross section exposed to elevated temperatures, and considering the indirect thermally-induced effects. The conditions of equilibrium and compatibility are met by taking into account themaximum permissible temperature-dependent strains for steel and concrete given in EN 1992-1-2.

\section{FIRE EXPOSURE CURVE}

The most common fire exposure curve used for routine fire structural design is the nominal fire exposure curve according to EN 1991-1-2 whereas for road tunnels in Germany the ZTV-ING Curve according to (BASt, 2013)has to be applied. The tunnel shall be designed for the fire situation by considering the high possibility of several vehicles being involved in fire ignition and the fire rate of $100 \mathrm{MW}$ (Schülter, 2014). Thus the increase rate of temperature within the first five minutes from the start of ignition (see figure 2) is very high. Further for the long period of 25 minutes, temperature remain constant, $1200{ }^{\circ} \mathrm{C}$, which is totally different from the nominal fire exposure curve having a continuous trendwhere the ambient temperature reaches 1006 ${ }^{\circ} \mathrm{C}$, gradually, after 90 minutes.

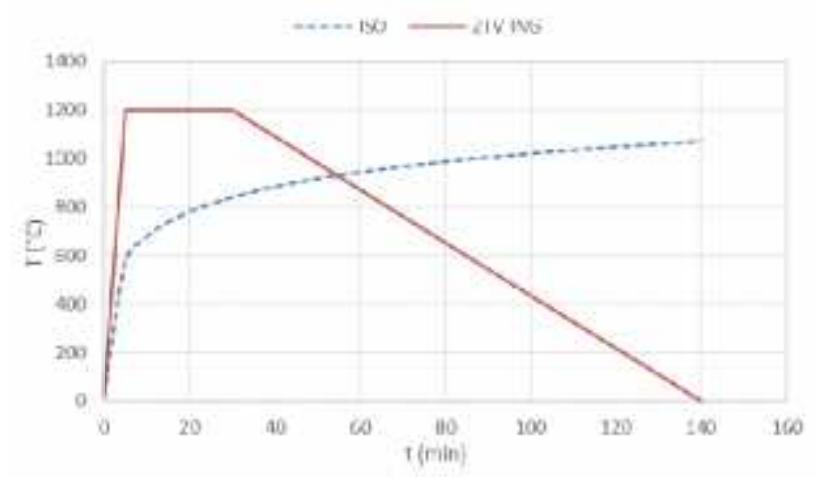

Fig.2Nominal Fire Exposure Curve vs ZTV-ING Fire Exposure Curve(BASt, 2013) 


\section{THERMAL ANALYSIS}

In order to find the best approximation of heat transfer through the concrete elements, thermal analyses of five concrete samples with different thicknesses of 80,90,100,110, 120 and $130 \mathrm{~cm}$ have been performed for 90 minutes. Time intervals of 5 and10 minutes, for plate model, and 15 minutes, for beam model, were chosen to read the absolute temperatures after each step. For the part of tunnel beam with variable thickness between 90 and $120 \mathrm{~cm}$, a linear interpolation of temperatures after each time step is assumed to be applied on the elements laying in this range. The absolute temperature values corresponding to each time interval are read at different nodes across the thickness of concrete. 1D heat transfer is considered by assuming pure concrete as a homogenous and isotropic material. Fourier's law of heat conduction is used for the energy transfer in temperature gradients directions with the upper limit of thermal conductivity of concrete,$\lambda_{c}=$ $1.951 \mathrm{~W} / \mathrm{Km}$, for the normal concrete corresponding to $20^{\circ} \mathrm{C}$ according to EN 1992-1-2. Further, absolute temperature values as a function of time according to ZTV-ING Fire Exposure Curve were applied at the exposed edges. The Newton's law of convection with the heat convection coefficients of $\alpha_{c}=25$ and correspondingly $\alpha_{c}=50 \mathrm{~W} / \mathrm{m}^{2} \mathrm{~K}$ are used. To find the effect of emissivity, $\varepsilon$, (Peter, et al., 2013) studied two values of emissivity of 0.7 and 0.8 on the absolute temperatures within a concrete element and concluded that for the depth of $10 \mathrm{~cm}$ from the exposed surface there was a temperature difference of $10{ }^{\circ} \mathrm{C}$ and for the deeper layers there is no influence on the absolute values of temperature. Thus Stefan-Boltzmann law is assumed with the emissivity grade of 0.8 . Figure 3 shows how temperature values vary as a function of time on 6 layers across the halfthickness of an $80-\mathrm{cm}$ thick concrete element till 90 minutes. It is to be noted that temperatures on the boundary, corresponding to node 51, tend to increase with a slower rate compared to the temperatures according to ZTV-ING Curve up to 30 minutes. From 30 to 90 minutes there is a reversed trend. As fire starts to vanish, the effective temperature decreases with a slower rate due to the thermal capacity of the concrete. Further, figure 3 shows that the temperature within the element affects, more dominantly, only the material properties of the cross sections laying between the exposed surfaceto the distance of $8 \mathrm{~cm}$ within the element where temperature has reached around $200^{\circ} \mathrm{C}$ after 90 minutes. From thispoint towards the middle of the concrete there is no significant influence on the material properties (from node 52 to 56 ).
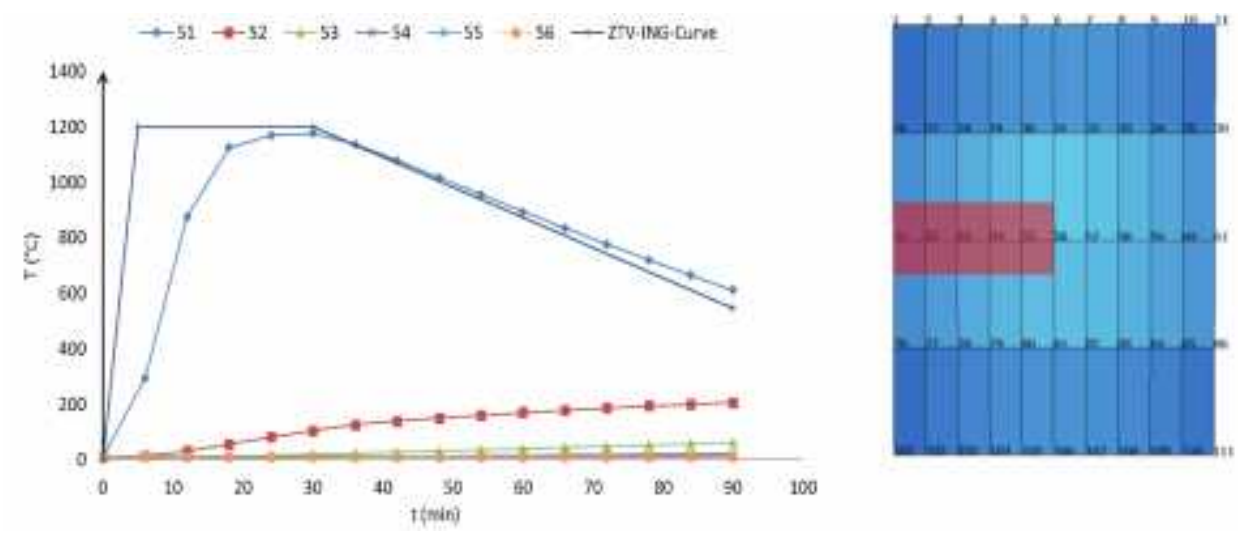

Fig.3Temperature curves for an 80-cm-thick element at different nodes(Pouran \& Harte, 2014)

\section{2D FE ANALYSIS OF TUNNEL WITH BEAM ELEMENTS}

To analyse the structure an elastically bedded beam modelwas chosenwithinprogram moduleTALPA (SOFiSTik, 2014). The beam element is discretized as a "fibre-beam-element", where the nonlinear, temperature-dependent material behaviour of reinforced concrete isconsidered in different layers corresponding to each time step. Furthermore, the material damagesobtained by previous analysis stepsaretransferred to the subsequent calculation steps. 
The tunnel fire action according to ZTV-ING Fire Exposure Curve (figure 2) was set in the left cell of the tunnel. Figure 4 showsthe bending moments at 90 minutes after the start of fire with the maximum bending moment of $2557 \mathrm{kNmat}$ the intersection of the upper beam and the middle wall.

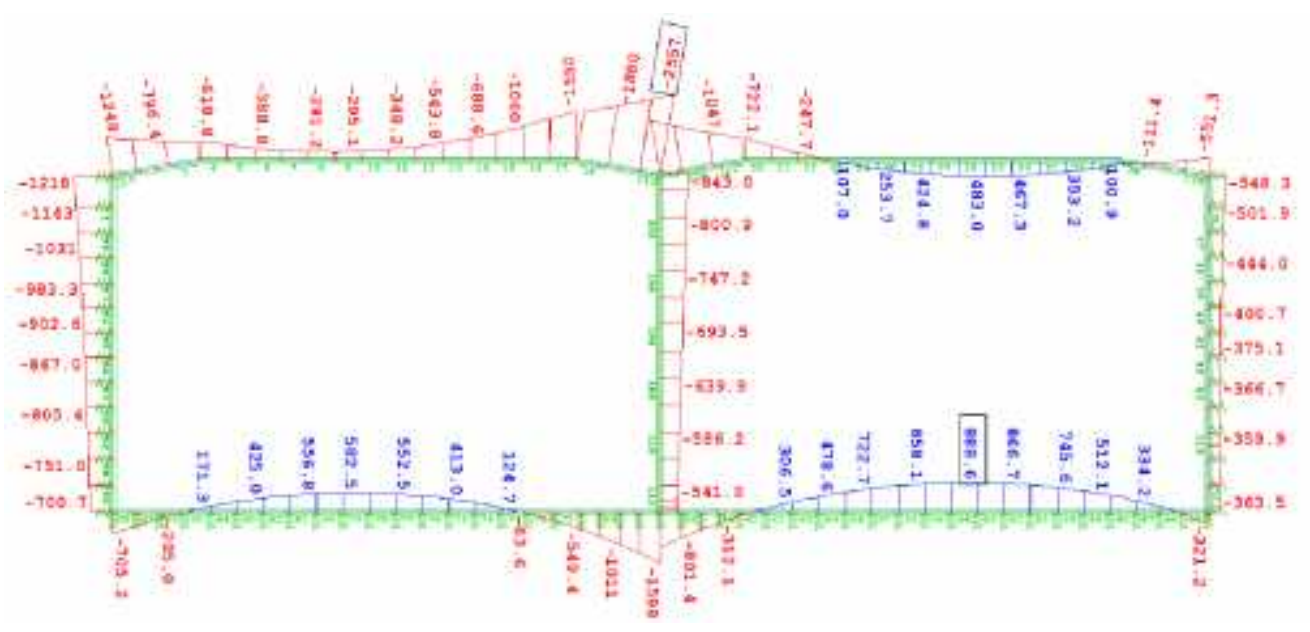

Fig.4Bending moment at $\mathrm{t}=90 \mathrm{~min}$ for accidental design situation, fire (Peter \& Nasseri, 2015)

\section{2D FE ANALYSIS OF TUNNEL WITH PLATE ELEMENTS}

The aim of generating another model with plate element properties within ASE program module (SOFiSTiK, 2013)is to have a comparable model consisting of similar boundary and element geometrical conditions. This is considered by using a symmetric 3D model with plate elements for 1 meter strip of tunnel having the same degrees of freedom as a 2D model.Symmetry boundary conditions on edges of beams and walls being perpendicular to the tunnel road direction are considered.

For the fire design of the tunnel, once again having the left cell exposed to fire (figure 5), nonlinear material model is assumed. This is performed by combining the multi-layered strain model(Harte, et al., 2000), taking account of strain induced by thermal effects, with the pre-damage strain-stress model. The latter takes account of the reduced material strength corresponding to thermal and loading effects at each previous time step as initial governing statefor the subsequent step of analysis.

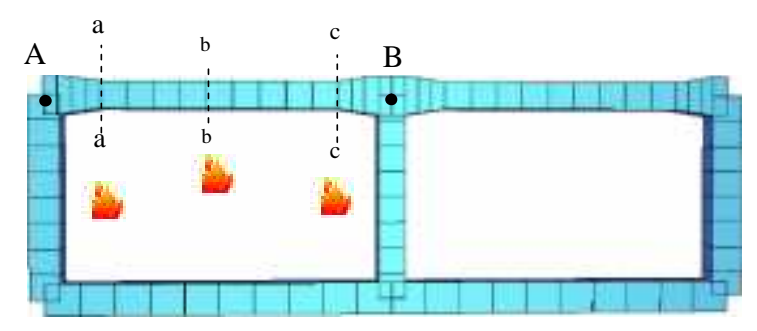

Fig.5 Symmetric plate model with walls and ceiling of the left cell exposed to fire simultaneously

The effects of actions from the normal design situation, therefore, are to be considered and combined with the thermal effects at each time step. Since, in case of fire situation, the flexural moments due to thermal constraints induce concave downward bending which act in the opposite direction compared to the mechanical induced bending moment as shown in figure 6, provision of minimum reinforcement close to both surfaces of concrete (exposed and unexposed) in the direction along the beam axis is required. 


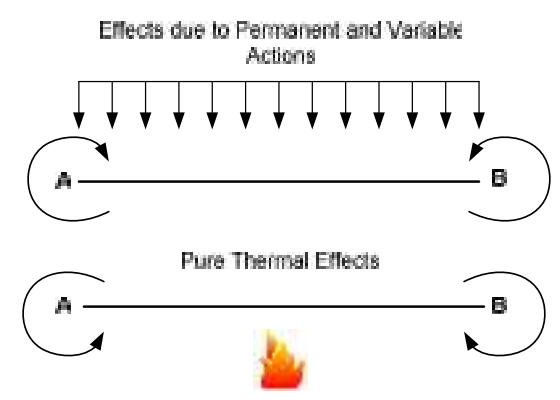

Fig.6Flexural bending moment induced by transverse loading and by pure thermal effects

Based on 10-minute time intervals and nonlinear analysis, the stresses according to each time step plotted and the ultimate limit strength verification of the system for the whole duration of 90 minutes is carried out. The critical points at which the plastic hinges might be developed are identified and possibility of failure by developing further plastic hinges according to different reinforcement ranges were analysed. By reaching 30 minutes, as shown in figure 7 , the cross section a-a is able to resist the maximum relative bending moment of approximately $73 \%$ greater than a moment applied just after the ignition of fire. This is due to the simultaneous increase of tensile stresses on the upper part of beam due to thermal induced bending moments and reduced cross sectional properties. The following possible mechanical failure mechanisms are to be considered:

- ductile tensile failure due to insufficient reinforcement and thus tensile resistance on the upper side of beams at joints and frame top corners (vertical cross sections intersecting points $A \& B$ and cross section $b-b$, figure 5);

- semi ductile tensile failure of upper reinforcement of beams due to lack of anchorage length for the fire situation (cross section a-a and c-c , figure 5);

- brittle failure of concrete in compression zone as a consequence of further increase of depth of tension zone and reduced strength in the reinforcement within the compression zone(in the haunch sections, figure 5).

Further following inaccuracies are not avoidable for the considered model:

- the bending moment values of the model with plate elements at Gauss points at the intersection between beams and walls are not identical due to the approximate character of shape functions for plate elements, figure 7 ;

- the symmetric model assumed due to limitation of the multi-layered strain modelin case of plate elements which does not give the best realistic possible geometrical properties of the tunnel;

- the effects of time intervals chosen for the analysis.

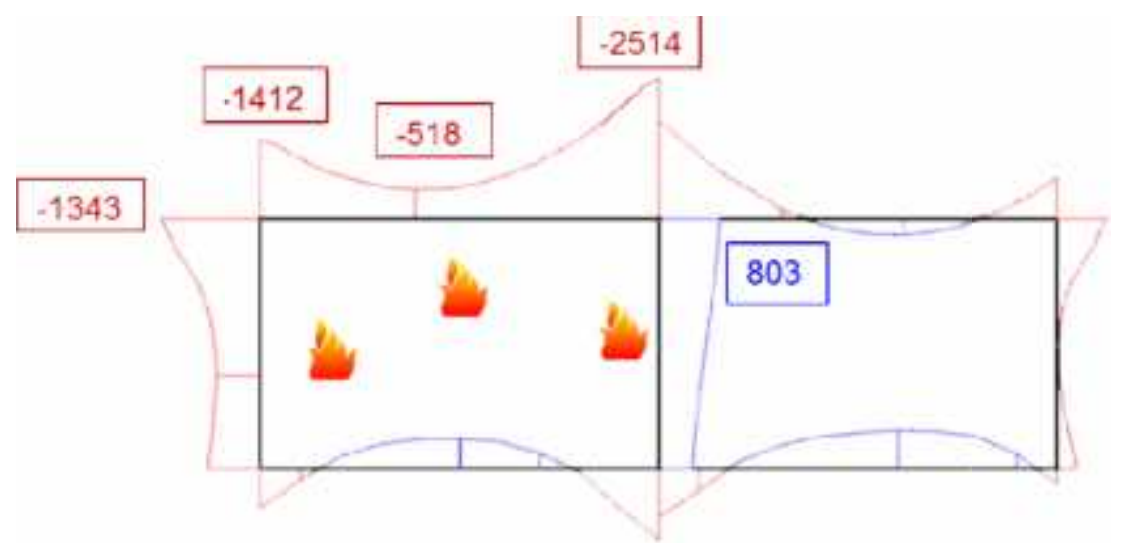

Fig.7Bending moment diagram for $\mathrm{t}=30$ minutes(Pouran \& Harte, 2014) 
In addition to the above mentioned factors, choice of time intervals, residual force tolerance at nodes and number of stain layers defined within concrete elements affect the analysis to some extent.

\section{DISCUSSION AND CONCLUSION}

Comparison made between the two models shows a good agreement in terms of maximum ultimate relative stresses which can be resisted over different time steps at point $\mathrm{B}$ where the induced relative bending momentshave the maximum value of $2557 \mathrm{kNmand} 2514 \mathrm{kNm}$ according to beam and plate models respectively. However, these two moments occurred at different time steps. There might exist several sources causing this deviation like the difference between time intervals which were 10 minutes for the case of plate elements and 15 minutes for the beam model. The lower the duration of time intervals, the more accurate damage behaviour of the cross section can be considered at different time steps. Further, both models showed a good consistency in terms of points with the highest risk of failure and mechanism due to which the structure can collapse or fail. The results of the verification for structural fire resistance according to the advanced calculation method proposed in EN 1992-1-2 differ from the simplified calculation method considering a temperature gradient of $50 \mathrm{~K}$ proposed by ZTV-ING(BASt, 2013). Especiallyin case of concrete components with large thickness, bending moments obtained by the simplified calculation methodare too large in comparisonwiththe corresponding values estimated by the advanced calculation method.

Thus a new approach has been developed in which theconsidered temperature gradient, $\Delta \mathrm{T}_{\mathrm{M}}$, is dependent on the thickness ( $\mathrm{t}$ )of thecorrespondingconcrete member.Starting froma linear temperature gradient, $\Delta \mathrm{T}_{\mathrm{M}}=55 \mathrm{~K}$ for $\mathrm{t}=60 \mathrm{~cm}$, this approach offers to, linearly, decrease the $\Delta \mathrm{T}_{\mathrm{M}}-$ values down to $\Delta \mathrm{T}_{\mathrm{M}}=25 \mathrm{~K}$ for $\mathrm{t}=150 \mathrm{~cm}$. In this approach, the further reduction of thermal stresses in case of reduced stiffness due to concrete cracking is not permitted, linear-elastic material properties need to be assumed. Nevertheless, this approach allows the design of fire exposed tunnels without time-consuming nonlinear analyses and thus might help to design tunnels more practically.

\section{ACKNOWLEDGEMENTS}

The financial support by theBundesanstaltfürStraßenwesenBASt is gratefully acknowledged.

\section{REFERENCES}

BASt, B. f. S., 2013. Zusätzliche Technische Vertragsbedingungen und Richtlinien für Ingenieurbauten (ZTV-ING) Teil 5 "Tunnelbau" und Teil 3 "Massivbau", Abschnitt 1 "Beton". s.l.ss.n.

Harte, R., Krätzig, W. B., Noh, S. Y. \& Petryana , Y. S., 2000. On progressive damage phenomena of structures. Computational Mechanics, Volume 25, pp. 404-412.

Peter, C., Knief, J., Schreyer, J. \& Piazolla, A., 2013. Rechnericher Nachweis des baulichen Brandschutzes für Tunnel in offener Bauweise, Schlussbericht zum FE Projekt 15.0502/2010ERB im Auftrag des BMVBS/ der BASt, s.l.: s.n.

Peter, C. \& Nasseri, A., 2015. Erprobung des rechnerischen Brandschutznachweises für Tunnel in offener Bauweise, Schlussbericht zum Projekt FE 15.0582/2013/FRB, s.l.: s.n.

Pouran, O. \& Harte, R., 2014. Prüfgutachten HH 02/14-1 zum Forschungsprogramm Straßenwesen FE 15.0582/2013/FRB Erprobung des rechnerischen Brandschutznachweises für Tunnel in offener Bauweise, s.l.: s.n.

Schülter, A., 2014. Passive Fire Protection for Tunnels: Guidelines, Parameters, Reality and suitable Measures. Tunnel, 7.pp. 22-33.

SOFiSTiK, 2013. ASE, General Static Analysis of Finite Element Structures Manual Version 27.14. Oberschleissheim: SOFiSTiK AG.

SOFiSTik, 2014. TALPA Statics of Plane or Axissymmetric Geomechanical Structures, Manual Version 14.05. Oberschleissheim: SOFISTIK AG.

SOFiSTiK, 2014. Teddy Version 12.20-27. Oberschleissheim: SOFiSTiK AG. 